\title{
Proposições do Plano Municipal de Educação de Jataí/GO: incertezas para a formação e trabalho docente
}

\author{
Belarmina Vilela Cruvinel ${ }^{1}$ \\ https://orcid.org/0000-0002-2604-1877 \\ Camila Alberto Vicente de Oliveira ${ }^{2}$ \\ https://orcid.org/0000-0002-0614-4481 \\ Egeslaine de $\mathrm{Nez}^{3}$ \\ https://orcid.org/0000-0002-0316-0080
}

\section{Resumo}

Este estudo apresenta o Plano Municipal de Educação (PME) de Jataí/GO destacando as metas e estratégias que se referem à formação e trabalho docente, especificamente no que tangencia a promoção da carreira do profissional da educação. Pretende, ainda, debater essas proposições do PME local tendo por base o Plano Nacional de Educação (PNE) e as incertezas em relação à formação e trabalho docente advindas do monitoramento e avaliação da implementação das metas e estratégias desse Plano. Tendo por base o levantamento documental com abordagem qualitativa, espera-se responder a seguinte problemática: pode o PME de Jataí/GO contribuir para a conformação de uma política educacional local que contribua para o avanço na formação e no trabalho/carreira docente? Percebe-se que o PME em tela tem avançado lentamente no que se refere às condições de trabalho docente minimizando, portanto, a sua relevância e gerando incertezas para a educação de qualidade social no município pesquisado.

Palavras-chave: Trabalho docente. Plano Municipal de Educação. Formação docente.

\begin{abstract}
This study presents the Municipal Education Plan (PME) of the municipality of Jataí/GO, where we highlight the goals and strategies that refer to teacher training and teaching work, specifically regarding the promotion of the career of the education professional. This study also intends to discuss these local PME propositions based on the National Education Plan (PNE) and the uncertainties regarding teacher training and work arising from the monitoring and evaluation of the implementation of the goals and strategies of this Plan. Based on the documentation survey with qualitative approach, it is expected to answer the following problematic: can the PME of Jataí/GO contribute to the shaping of a local educational policy that contributes to the advancement in teachers' training and work/career? We notice that the PME in question has been slowly advancing in what relates to teaching work conditions, thus minimizing its relevance and generating uncertainties for social quality education in the researched municipality.
\end{abstract}

Keywords: Teaching work. Municipal Education Plan. Teacher training.

\footnotetext{
${ }^{1}$ Mestranda em Educação - Programa de Pós-Graduação em Educação - Universidade Federal de Goiás/Regional Jataí. Bolsista FAPEG. E-mail: dbelarminave@gmail.com

${ }^{2}$ Doutora em Educação. Docente do Curso de Pedagogia e do Programa de Pós-Graduação em Educação - Universidade Federal de Goiás/Regional Jataí. E-mail: camilaoliveira.ufg@gmail.com

3 Pós-doutoranda em Educação - PUCRS - Bolsista PNPD/CAPES. Doutora em Educação. Docente do Campus Universitário do Araguaia Universidade Federal de Mato Grosso. E-mail: profe.denez@gmail.com
} 
Introdução

Este artigo objetiva apresentar e analisar o PME de Jataí/GO destacando as metas e estratégias que se referem à formação e trabalho docente, especificamente no que tangencia a promoção da carreira do profisssional da educação no referido município. Pretendeu, ainda, debater essas proposições do PME local tendo por base o PNE e as incertezas em relação à formação e trabalho docente advindas do monitoramento e avaliação da implementação das metas e estratégias desse Plano.

O presente estudo insere-se em uma pesquisa interinstitucional cujo objeto é o papel dos Conselhos Municipais de Educação (CME) na implementação dos Planos Municipais de Educação (PME), com vistas a contribuir com a qualidade socialmente referenciada da educação pública. Tal investigação, coordenada pela Universidade Federal de Uberlândia (UFU) é desenvolvida em parceria com a UFG/Regional Jataí-GO, Universidade Federal de Mato Grosso (UFMT), Campus Universitário do Araguaia (CUA), Universidade do Estado de Mato Grosso (UNEMAT) e Universidade Federal da Grande Dourados (UFGD).

Partimos do pressuposto que a reforma do sistema político brasileiro se fundamenta na crise do estado burocrático que deu suporte a um novo grupo hegemônico com políticas neoliberais, as quais se utilizam das fragilidades do sistema em crise para justificar propostas de mudança urgente. A relação entre o trabalho e a educação sofreu influências de correntes conservadoras e liberais, a partir dos anos 1970, porém, no Brasil, a reestruturação do modo de produção toma força na década de 1990, com a mudança da administração pública burocrática para a gerencial. Desde então, as políticas públicas vêm se desenvolvendo numa conjuntura em que a globalização se impõe como obrigatória; e, as relações entre o Estado, o poder e a política sustentam ações subsidiadas e implementadas a partir dos governos, sejam estaduais ou municipais.

Nesse contexto, torna-se relevante ressaltar os Planos de Educação na organização da política educacional, especialmente, ao que se refere à concepção de trabalho e formação docente (inicial, pós-graduação e desenvolvimento profissional). Neste estudo, focalizam-se as proposições do PME de Jataí, município do interior goiano, no que tange à carreira dos profissionais da educação, com o objetivo de responder à seguinte problemática: pode o PME de Jataí/GO contribuir para a conformação de uma política educacional local que contribua para o avanço da formação e do trabalho/carreira docente?

Este artigo encontra-se dividido em quatro partes, além das considerações iniciais e finais. Na primeira, enfatiza-se a construção do PME; na segunda parte, os procedimentos metodológicos da pesquisa são desvelados; o trabalho docente é o foco da terceira parte; e, por fim, destaca-se o monitoramento e avaliação do PME de Jataí/ GO, em que são apresentados os resultados obtidos.

\section{Construção do Plano Municipal de Educação}

A reforma do sistema político brasileiro teve sua fundamentação na crise do estado burocrático que justificou a adoção do modelo gerencialista. Dessa forma, as políticas neoliberais são estruturadas pelo regime de acumulação do capital, modo de regulação e organização do trabalho (HELOANI, 2018). 
A educação, nesse contexto, tem um papel fundante na concretização do novo modelo gerencial, adequando-o às demandas do capital. Na década de 1990, o campo educacional passa a ser pensado e planejado por grandes corporações educacionais, as quais desqualificam o ensino vigente para a capacitação de recursos públicos. Entretanto, os pesquisadores educacionais buscam resistir ao avanço desordenado das ideologias neoliberais para os trabalhadores docentes, e esse se dá, ora de forma mais lenta, ora mais rapidamente (HELOANI, 2018).

Os estudos de Heloani (2018, p. 103) apontam que os pensamentos liberais atuais "são herdeiros de duas tradições ideológicas que se foram fundindo durante o século XIX, isto é, o pensamento liberal e o conservador”. Partindo dessa união, o neoliberalismo econômico tem sua gênese na corrente conservadora, porém com ideias econômicas liberais, na qual o Estado reduz-se no que se refere às questões sociais enquanto expande-se para o capital.

Para Frigotto (2016, p. 61), o capitalismo, na contemporaneidade, tem "sua afirmação hegemônica de acumulação real, a capacidade de superar suas crises cíclicas lhe devolve a energia inicial para recompor-se, efetivamente, o capital, sua ciência e ideologia”.

Nesse sentido, a regulação normativa no Brasil inicia-se com os princípios democráticos liberais, na década de 1980, com a promulgação da Constituição da República Federativa do Brasil (CF, 1988). Contudo, a efetivação dos princípios neoliberais se deu nos anos de 1990, com a Reforma do Estado, no governo Fernando Henrique Cardoso. Na educação, as expressões do gerencialismo neoliberal podem ser observadas, tais como: gestão administrativa, flexibilização na formação e no trabalho docente e do sistema de ensino, eficiência, eficácia e controle, os quais se estabeleceram com a aprovação da Lei de Diretrizes e Bases Nacional de Educação (LDB, 1996) e com os Planos Nacionais de Educação (2001 e 2014).

A Emenda Constitucional (EC) n. 14 de 1996 modifica a redação do artigo 211 da CF/1988, assim definindo competências específicas dos entes federados acerca do ensino e em regime de colaboração, fícando estabelecido que: “§2ºs Municípios atuarão prioritariamente no ensino fundamental e na educação infantil”. No artigo 211, A União, os Estados, o Distrito Federal e os Municípios organizarão, em regime de colaboração, seus sistemas de ensino. Portanto, a EC n. 53 de 2006 inclui o " $\$ 5^{\circ}$ A educação básica pública atenderá prioritariamente ao ensino regular" (BRASIL, 2018, p. 162).

Por sua vez, a EC n. 59/2009 modifica a redação do artigo 214 da CF/1988, efetivando a obrigatoriedade da elaboração do PNE, devendo traçar as diretrizes, objetivos, metas e estratégias como forma de "articular o sistema nacional de educação em regime de colaboração" (BRASIL, 2018, p. 163). Desse modo, no artigo 87, nas disposições transitórias da LDB de 1996, institui-se a Década da Educação em consonância com a Declaração Mundial sobre Educação para Todos, documento esse que tem seus princípios fundantes no gerencialismo que permeia também os PNEs de 2001 e 2014 (BRASIL, 2017, p.52).

De acordo com a Shiroma e Evangelista (2015), as reformas versaram sobre o trabalho, formação e carreira docente, uma vez que o mercado demandava trabalhadores com um mínimo de escolarização. Com isso, expandiuse o número de matrículas da educação básica, aumentando a oferta de vagas no ensino público e exigindo um maior número de profissionais docentes para atenderem essa demanda.

No bojo desse processo, o PNE (2014-2024) colocou com a exigência de que os municípios traçassem metas de longo prazo, ou seja, para os próximos dez anos (BRASIL, 2014a). Vale, portanto, compreender como esse processo tem se dado localmente, no caso do Plano Municipal de Educação de Jataí (PME), instituído pela 
Lei de n. 3708/2015 (JATAÍ, 2015). A cidade de Jataí está localizada no sudoeste goiano e é destaque no campo econômico e educacional, uma vez que além da educação infantil, ensino fundamental I e II, ensino médio, há uma Universidade Federal, uma Universidade Estadual, um Instituto Federal e outras instituições de ensino superior privadas com ensino presencial ou à distância (JATAÍ, 2015).

Idealmente, o PME, por ser uma política de longo prazo, deveria transpassar os mandatos políticos eletivos e, portanto, ser entendido como uma ação de Estado. No caso do município de Jataí, a estrutura desse Plano Municipal segue a estrutura organizacional do Plano Nacional.

O documento do Ministério da Educação "Plano Nacional de Educação: Conhecendo as 20 metas" destaca que "há metas estruturantes para a garantia do direito à educação básica com qualidade". O primeiro grupo de metas são as nove metas de universalização e expansão: as três primeiras tratam da universalização a atendimento na educação infantil, ensino fundamental de nove anos e população de 15 a 17 anos; as metas 10 e 11 da ampliação do número de matrículas; a meta 05 versa sobre alfabetização; a meta 06 sobre educação de tempo integral; a meta 07 sobre a elevação do Ideb; a meta 09 aborda a erradicação do analfabetismo e redução o analfabetismo funcional (BRASIL, 2014b, p. 09).

No segundo bloco, a meta 04 dispõe sobre o ensino para os alunos com deficiências e a meta 08 prevê a elevação da escolaridade da população de 18 a 29 anos. No terceiro agrupamento encontram-se as metas da valorização dos profissionais da educação, tais como: a meta 15 , a qual destaca que os órgãos governamentais devem garantir que os profissionais da educação tenham formação no ensino superior e na sua área de atuação; a meta 16 indica a elevação da formação continuada dos profissionais da educação; a meta 17 aborda a valorização dos profissionais da educação básica; e a meta 18, a efetivação do plano de carreira (BRASIL, 2014b).

No grupo quatro das metas do PNE (2014-2024) encontra-se o ensino superior, que são: a meta 12 versando sobre a elevação de matrículas para o ensino superior, "no segmento público"; a meta 13, por sua vez, elevação da qualidade da educação e ampliar o corpo docente para mestres e doutores; e a meta 14, elevação de matrícula para formação continuada. Por fim, a meta 19 que dispõe acerca da gestão e a meta 20, a respeito de financiamento, é a que tem papel primordial nesse planejamento porque sem que haja os recursos destinados para cada setor aqui exposto, qualquer política pública tende a fracassar (BRASIL, 2014b, p. 13).

Essa apresentação organizacional do PNE faz-se necessária, uma vez que o Plano Municipal de Educação de Jataí/GO segue o padrão apresentado acima. Porém, quanto às estratégias há algumas variações. Avançando na resposta à problemática do estudo em tela, analisa-se como vêm se desenvolvendo as metas e estratégias do segundo grupo, as quais versam sobre a formação e o trabalho/carreira docente por meio dos relatórios de monitoramento e avaliação do PME de Jataí/GO.

Como afirmado, em consonância com o segundo bloco de metas do PNE (2014-2024), o PME de Jataí/GO apresenta as metas dispostas no quadro a seguir, as quais se referem - como no similar nacional - à formação e ao trabalho docente. 


\section{Quadro 1 - As metas do PME de Jataí - GO}

\begin{tabular}{|c|c|c|c|}
\hline Meta 15 & Meta 16 & Meta 17 & Meta 18 \\
\hline $\begin{array}{l}\text { Garantir, em regime de } \\
\text { colaboração entre a União, os } \\
\text { Estados, o Distrito Federal e } \\
\text { os Municípios, no prazo de } \\
1 \text { (um) ano de vigência deste } \\
\text { PME, política nacional de } \\
\text { formação dos profissionais } \\
\text { da educação de que tratam } \\
\text { os incisos I, II e III do caput } \\
\text { do art. } 61 \text { da Lei no 9.394, } \\
\text { de } 20 \text { de dezembro de 1996, } \\
\text { assegurado que todos os } \\
\text { professores e as professoras } \\
\text { da educação básica possuam } \\
\text { formação específica de nível } \\
\text { superior, obtida em curso } \\
\text { de licenciatura na área de } \\
\text { conhecimento em que atuam. }\end{array}$ & $\begin{array}{l}\text { Formar, em nível de pós- } \\
\text { graduação, } 50 \% \text { (cinquenta } \\
\text { por cento) dos professores } \\
\text { da educação básica, até o } \\
\text { último ano de vigência deste } \\
\text { PME, e garantir a todos } \\
\text { (as) os (as) profissionais da } \\
\text { educação básica formação } \\
\text { continuada em sua área de } \\
\text { atuação, considerando as } \\
\text { necessidades, demandas } \\
\text { e contextualizações dos } \\
\text { sistemas de ensino. }\end{array}$ & $\begin{array}{l}\text { Valorizar os (as) profissionais } \\
\text { do magistério das redes } \\
\text { públicas de educação básica } \\
\text { de forma a equiparar seu } \\
\text { rendimento médio ao dos } \\
\text { (as) demais profissionais com } \\
\text { escolaridade equivalente, } \\
\text { até o final do sexto ano de } \\
\text { vigência deste PME. }\end{array}$ & $\begin{array}{l}\text { Assegurar, no prazo de } 2 \\
\text { (dois) anos, a existência de } \\
\text { planos de Carreira para os } \\
\text { (as) profissionais da educação } \\
\text { básica e superior pública de } \\
\text { todos os sistemas de ensino } \\
\text { e, para o plano de Carreira } \\
\text { dos (as) profissionais da } \\
\text { educação básica pública, } \\
\text { tomar como referência o piso } \\
\text { salarial nacional profissional, } \\
\text { definido em lei federal, nos } \\
\text { termos do inciso VIII do art. } \\
206 \text { da Constituição Federal. }\end{array}$ \\
\hline
\end{tabular}

Fonte: Cruvinel, Oliveira e Nez (2019). Dados extraídos do Lei 3.708/2015. Disponível em: <https://www.jatai.go.gov.br/secretaria-de-educacao/ plano-municipal-de-educacao/>. Acesso em: 30 ago. 2019.

Como pode ser observado no quadro 01 , a primeira e a última meta possuem interstício para execução de curto prazo, o qual não deve ultrapassar os primeiros cinco anos de sua vigência. Ou seja, já na implantação do PME, os professores da educação básica, para estarem em sala de aula, necessitam de formação em nível superior, bem como deve haver a efetivação do Plano de Carreira para esses profissionais logo no segundo ano de vigência dessa Lei Municipal. Na terceira meta, referente à equiparação salarial, seu cumprimento é de médio prazo (seis anos); e, por fim, a meta 16 não apresenta lapso temporal para sua efetivação, sendo considerada, assim, de longo prazo. Ressalta-se que os professores dessa rede municipal possuem o Estatuto e o Plano de Cargos e Vencimentos dos Profissionais do Magistério de Jataí/GO4, mas o PME orienta a sua revisão e reformulação.

Para compreender o desenvolvimento desse grupo de metas, que aborda a formação, o trabalho e a carreira dos docentes do município de Jataí/GO, faz-se mister recorrer a alguns fundamentos dessas categorias e sua relação com o PME.

\section{Procedimentos metodológicos}

Os procedimentos metodológicos desta investigação, no que diz respeito aos métodos e técnicas de coleta e análise de dados, teve como base a pesquisa exploratória. Para Gatti (2007, p.62-63), a pesquisa é um cerco ao problema. “[...] É necessário escolher instrumentos para acessar a questão, vislumbrar e escolher trilhas a seguir

\footnotetext{
${ }^{4}$ JATAÍ. Estatuto e o Plano de Cargos e Vencimentos dos Profissionais do Magistério do Município de Jataí-GO. Disponível em: $<\mathrm{http} / / /$ sislegis.camarajatai.go.gov.br/portal//seeker?iddoc=1210>. Acesso em: 13 maio 2019.
} 
e modos de se comportar nessas trilhas, criar alternativas de ação para eventuais surpresas, criar armadilhas para capturar respostas significativas".

Para a execução desse cerco ao problema foram realizadas várias etapas, uma delas foi a pesquisa bibliográfica, atividade constante de localização e consulta de fontes diversas de informações escritas, que serviu para coletar dados acerca da temática do trabalho docente.

A fim de contemplar os objetivos da pesquisa, foram levantados os conceitos de trabalho vital e o trabalho como mercadoria: sua natureza, material e não material, bem como, a relação com a educação na formação desse novo profissional. Esse levantamento propiciou a compreensão da reestruturação do trabalho docente, a partir da reforma educacional, que tem levado à sua precarização, com aumento da jornada de trabalho, flexibilização, descentralização gerencial e outros meios de controle.

Concomitantemente, a pesquisa documental do/no PME foi implementada no que diz respeito à formação e carreira dos profissionais de educação.

O corpus da pesquisa documental foram, prioritariamente, o PME e os relatórios de monitoramento e avaliação da execução do Plano, produzidos pelo Comitê Gestor e disponibilizados no sítio da Secretaria Municipal de Educação de Jataí/GO. Os documentos foram interpretados à luz da análise de conteúdo (BARDIN, 1977), levando em consideração uma proposta crítica de abordagem qualitativa, que se aproxima dos modelos compreensivos e interpretativos.

\section{O trabalho docente}

No atual estágio de desenvolvimento do sistema capitalista, percebe-se uma autorregulação das crises, que busca meios de expandir-se economicamente, aprimorando ainda mais o controle hegemônico. Segundo Frigotto (2016), a educação tem um papel de destaque nessa regulação, em especial, dos trabalhadores que devem ser resilientes, eficazes, eficientes e produtivos. Contraditoriamente, o capitalismo aumenta o trabalho em tempo parcial e terceirizado, reduzindo a parcela dos trabalhadores estáveis.

$\mathrm{O}$ trabalhador docente não foge a isso e a sua formação inicial e continuada, o trabalho e a carreira têm sido alvos de reformas educacionais desde a década de 1980, intensificadas a partir dos anos 1990 até os dias atuais. No campo das políticas educacionais essas reformas ficaram evidentes com a LDB/1996, o PNE (2014-2024), Resolução CNE/CP n. 1/2006 que efetivou as Diretrizes Curriculares Nacionais para o curso de Graduação em Pedagogia. Em consonância com as referidas leis em nível federal, a Lei n. 2.822/2007 do Estatuto e o Plano de Cargos e Vencimentos dos Profissionais do Magistério do Município de Jataí - GO se constitui enquanto uma normativa que regula o trabalho desses por meio de princípios neoliberais da eficiência e eficácia. Assim, o Estatuto do Magistério encontra-se adequado às Leis Federais n. ${ }^{\circ}$ 9394, de dezembro de 1996 e Medida Provisória n. ${ }^{\circ}$ 339, de 28 de dezembro de 2006 que institui o Fundo de Manutenção e Desenvolvimento da Educação Básica e de Valorização dos Profissionais da Educação - FUNDEB.

Partindo-se do trabalho como fundante dos processos de humanização é preciso compreender a relação existente entre o trabalho e a educação. A formação humana se dá, também, por meio da educação, a qual se procede na comunicação entre as pessoas, em relações marcadas por contradições e disputas em qualquer tempo e espaço (SAVIANI; DUARTE, 2010). 
A interação entre o homem e a natureza se desenvolve por meio do trabalho, conforme destaca Marx (1993, p. 14) ao afirmar que "o trabalho é mediação entre o homem e a natureza, e dessa interação deriva todo processo de formação humana". Por sua vez, Abaggnano (2007, p. 964) apresenta o trabalho como uma "atividade cujo fim é utilizar as coisas naturais ou modificar o ambiente e satisfazer às necessidades humanas”, ou seja, uma atividade criadora e transformadora. Para Saviani (1984, p. 1), o trabalho é uma ação intencional, e o mesmo "se instaura a partir do momento em que seu agente antecipa mentalmente a finalidade da ação. Consequentemente, o trabalho não é qualquer tipo da atividade, mas uma ação adequada a finalidades".

Nesse sentido, Abaggnano (2007, p. 964) conceitua a relação do homem com a natureza como sendo de

\begin{abstract}
1) Dependência do homem em relação à natureza, no que se refere à sua vida e aos seus interesses: isso constitui a necessidade, num de seus sentidos (v.); 2) reação ativa a essa dependência, constituída por operações mais ou menos complexas, com vistas à elaboração ou à utilização dos elementos naturais; 3) grau mais ou menos elevado de esforço, sofrimento ou fadiga, que constitui o custo humano do trabalho.
\end{abstract}

A relação do homem e natureza se efetiva por meio do trabalho humanizado, primeiramente, objetiva-se a consciência humana, a qual possibilitará a transformação de ambos, garantindo a sobrevivência da espécie. Porém, ao longo do tempo incorporam-se novos significados ao conceito de trabalho como sendo uma atividade remunerada. Diante disso, passa a ter característica de mercadoria.

O vocábulo "trabalho" na língua portuguesa classifica a palavra de formas variadas, porém para buscar o aprofundamento dessa categoria em sua totalidade é fundamental compreender o contexto econômico, político, social, cultural no qual ele se insere.

Diante disso, o trabalho é uma atividade coordenada que permeia o caráter físico e/ou intelectual. Nessa relação, o homem passa a produzir riqueza objetiva/material e subjetiva/intelectual com o produto do trabalho, mas deixa de percebê-lo, dialeticamente (SAVIANI; DUARTE, 2010).

Nesse sentido, Mascarenhas (2005, p. 51) pontua que, “a relação do ser humano com o trabalho não se dá como realização, criação, descaracterizando-se, comprometendo o próprio processo de humanização, a vivência do tornar-se humano, humanizado", de tal modo ficando difícil a (re)criação e a realização do trabalho, assim tornando-o alienado na sua totalidade, mas percebendo-o em partes.

Segundo Maggie Brasil (2005, p. 9) o "Capitalismo possui uma processualidade histórica que impõe e mantém uma realidade compatível com sua lógica, referendada por um processo de socialização humana da qual a base é construída pelo trabalho alienado". Nesse sistema, os processos de trabalho são "os resultados da produção material realizada pelas classes dominadas que beneficiam as classes dominantes" (SAVIANI; DUARTE, 2010, p. 426). Portanto, o objeto resultado desse trabalho se torna estranho e alheio ao trabalhador, pois uma parte do produto do trabalho é incorporado ao capital.

De acordo com Maggie Brasil (2005, p. 9-10) o trabalho manual e o intelectual são "atividades laborativas dissociadas". Para a autora, essa atividade "dissociada representa tanto na desvalorização da força de trabalho que é vendida isoladamente por um menor custo, como também implica diretamente num divórcio constante do próprio conhecimento quando qualifica trabalho manual dissociado de trabalho intelectual". (BRASIL, 2005, p.910). Dessa forma, a totalidade do objeto se torna estranhado para o trabalhador, e, esse processo se intensifica na gestão gerencialista. 
De acordo com Saviani e Duarte (2010, p. 427), as relações sociais do capitalismo são individualizadas, decompondo o trabalho humanizador. Diante disso, "desefetivação do trabalhador, transforma a objetivação em perda do objeto e servidão ao mesmo", a qual gera a desarmonia e a alienação. Assim, percebe-se que o trabalho alienado não se torna parte do seu ser, pois esse ato se torna um produto possível de venda (SAVIANI; DUARTE, 2010)

Acrescido a isso, Saviani (2015, p. 286) destaca que a educação é um trabalho não material que envolve "a produção de conhecimento, ideias, conceitos, valores, símbolos, atitudes e habilidades”. Nessa linha, o produto final da ação educativa seria o ensino, sobre o qual encontram-se correntes pedagógicas divergentes acerca de sua finalidade (SAVIANI; DUARTE, 2010). Desvelar as características da formação do trabalhador no estado neoliberal é condição para aprofundamento sobre a formação e o trabalho docente.

Analisando o PME do município de Jataí, verifica-se que em seu artigo $2^{\circ}$, é ressaltado que a "formação para o trabalho e para a cidadania, com ênfase nos valores morais e éticos em que se fundamenta a sociedade" (JATAÍ, 2015, p. 01). Diante disso, a questão que se impõe é saber que valores são esses? Para qual modelo de sociedade? A meta 15 do PME de Jataí estabelece que os profissionais da educação necessitam ser qualificados de acordo com área de atuação na educação básica, como evidencia o quadro n 01 .

Para tal, a Resolução 01/2006 prevê expansão de vagas nos cursos de licenciaturas em Pedagogia, cuja profissão não prescinde de conhecimento específico, visando uma educação para a cidadania, participação na gestão de modo a contribuir no funcionamento da instituição escolar. Ainda no quadro n. 01 é apresentada a redação da meta 16, na qual os professores devem elevar sua formação em nível de pós-graduação, ou seja, que haja uma formação contínua de acordo com as necessidades e demandas do trabalho docente.

Para Shiroma e Evangelista (2015, p. 316), o trabalho docente está na encruzilhada, ou seja, deve "possibilitar aos alunos da escola pública a apropriação do conhecimento socialmente produzido e sua formação como sujeito histórico, sua formação humana". No entanto, tais necessidades estão colocadas apenas no plano do discurso, pois, as políticas de formação de professores têm visado, sobretudo, o desenvolvimento de competências e habilidades. Isso pode ser verificado nos estudos de Shiroma e Evangelista (2015, p. 352) quando apontam que as Diretrizes Curriculares Nacionais para formação de professores do Curso de Pedagogia "reduziram a carga horária das disciplinas teóricas para ampliar as das práticas e gestão”.

Corroborando o que dizem as autoras, nota-se que a Resolução CNE/CP n. 1/2006 encontra-se permeada com esses princípios, como por exemplo: a gestão, no artigo $3^{\circ}$, inciso III - “a participação na gestão de processos educativos e na organização e funcionamento de sistemas e instituições de ensino". No artigo $5^{\circ}$ podemos destacar os trabalhos de cooperação entre instituições e sociedade civil, trabalho em equipe e outras. (BRASIL, 2006, p. 1). A desqualificação do professor e os baixos resultados nos desempenhos dos alunos justificam as mudanças nas Diretrizes dos cursos de licenciaturas visando, assim, a formação desse novo trabalhador (SHIROMA; EVANGELISTA, 2011).

A meta 17 do PME/Jataí/GO destaca a valorização dos profissionais do Magistério, compativelmente às demais categorias de trabalhadores com o mesmo de nível de formação, com a elevação do piso salarial. Shiroma e Evangelista (2011) afirmam que a valorização do trabalho docente passa por condições de serviços, salários compatíveis para subsistência, perspectiva de uma carreira e o reconhecimento social. Contudo, no estado gerencial, as políticas meritocráticas lançadas à carreira do professor levam ao esfacelamento do coletivo e uma busca 
exacerbada pelo destaque nos rankings nacionais, tornando-se um meio de controle do contingente de professores.

O Estatuto do Magistério da Rede Municipal de Jataí, no que tange à valorização dos profissionais, destaca no artigo $5^{\circ}$ e em seus oito incisos, o ingresso do profissional licenciado na carreira, formação contínua em serviço, piso salarial, data base para correção salarial, progressão vertical e horizontal, condições reservadas para estudos e a liberdade de expressão no exercício profissional (JATAÍ, 2007). No entanto, a análise dos relatórios de monitoramento e avaliação do PME, permite uma compreensão singular a respeito da relação entre formação, trabalho e carreira docente nesse município.

\section{Monitoramento e avaliação do PME de Jataí - GO}

A efetivação do Plano Municipal de Jataí necessita ser monitorada continuamente mediante avaliações periódicas que competem aos órgãos descritos no artigo $7^{\circ}$ e seus cinco incisos da Lei n. 3.708/2015: "Secretaria Municipal de Educação; Comissão de Educação do Legislativo Municipal; Conselho Municipal de Educação; Fórum Municipal de Educação; Conselho de Acompanhamento e Controle Social” (JATAÍ, 2015, p. 1).

No portal do Ministério da Educação, PMEs em movimento, encontra-se uma plataforma denominada "Rede de Assistência Técnica para Monitoramento e Avaliação dos Planos de Educação, cujo objetivo é subsidiar as comissões coordenadoras responsáveis por esta finalidade nos estados, no Distrito Federal e nos municípios" (BRASIL, 2019, p. 1).

No quadro que segue pode-se ter uma melhor compreensão desse processo de avaliação das metas e estratégias, por meio da visualização dos relatórios de monitoramento dos anos 2016, 2017 e 2018, os quais permitem compreender seus efeitos e incertezas sobre a formação e o trabalho docente no município.

Quadro 2 - Relatórios de monitoramento e avaliação do PME de Jataí - GO

\begin{tabular}{|c|c|c|}
\hline Relatório Monitoramento 2017 & $\begin{array}{l}\text { Relatório de Avaliação do biênio } \\
2015 / 2017^{1}\end{array}$ & Relatório de monitoramento 2018 \\
\hline $\begin{array}{l}\text { Meta } 15 \text { - Não há dotação } \\
\text { orçamentária tipificada no } \\
\text { Orçamento Municipal de Jataí de } \\
2017 \text { para a execução desta meta. } \\
\text { Os investimentos incidem nos } \\
\text { orçamentos da Educação Infantil e do } \\
\text { Ensino Fundamental. }\end{array}$ & $\begin{array}{l}\text { Meta } 15 \text { - Das } 05 \text { estratégias } \\
\text { elaboradas: } 03 \text { foram estão sendo } \\
\text { executadas e } 02 \text { não foram cumpridas. }\end{array}$ & Meta 15 - Em branco \\
\hline
\end{tabular}




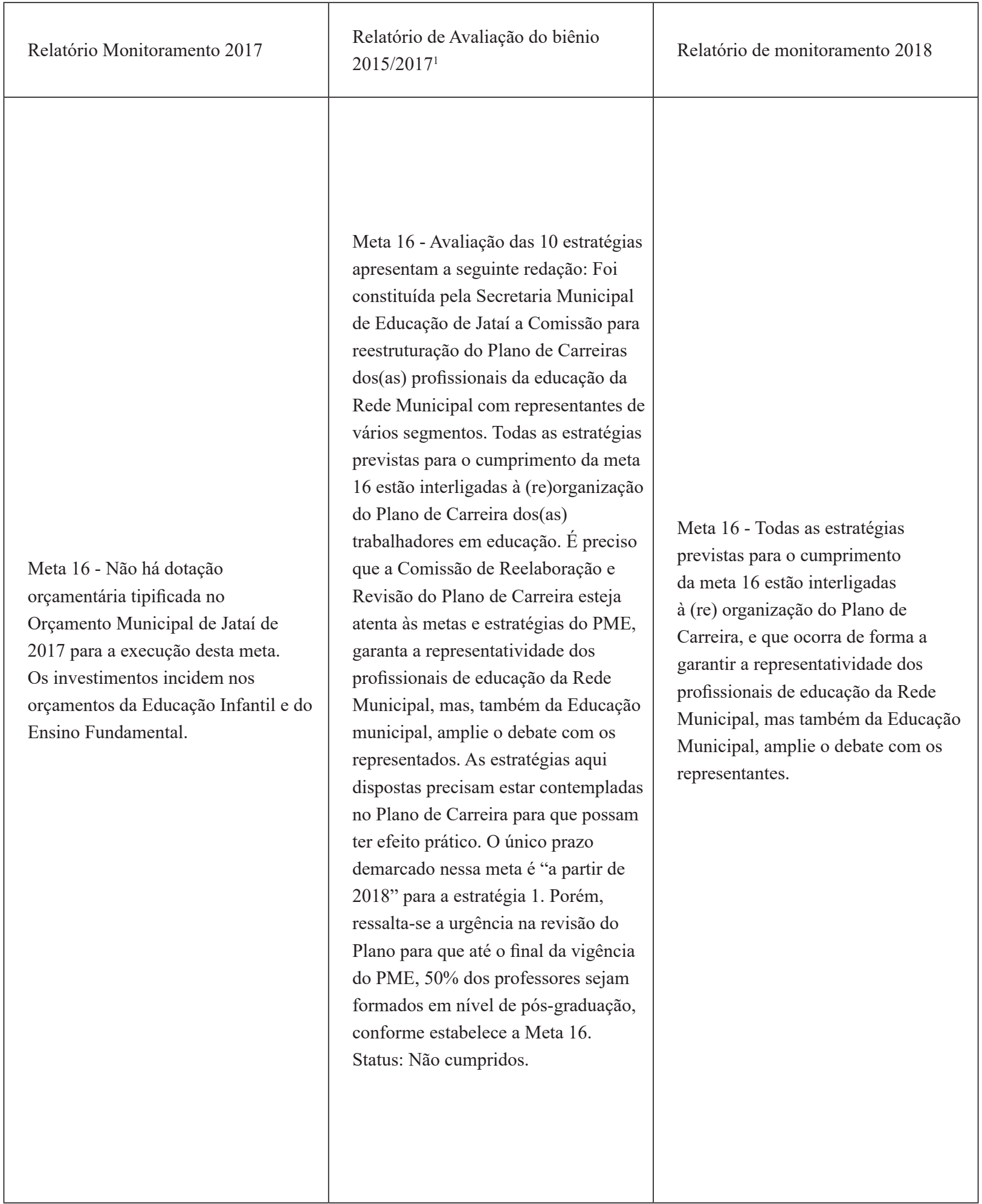




\begin{tabular}{|c|c|c|}
\hline Relatório Monitoramento 2017 & $\begin{array}{l}\text { Relatório de Avaliação do biênio } \\
2015 / 2017^{1}\end{array}$ & Relatório de monitoramento 2018 \\
\hline $\begin{array}{l}\text { Meta } 17 \text { - Não há dotação } \\
\text { orçamentária tipificada no } \\
\text { Orçamento Municipal de Jataí de } \\
2017 \text { para a execução desta meta. } \\
\text { Os investimentos incidem nos } \\
\text { orçamentos da Educação Infantil e do } \\
\text { Ensino Fundamental. }\end{array}$ & $\begin{array}{l}\text { Meta } 17 \text { - Avaliação das } 04 \\
\text { estratégias: } 01 \text { - O Piso Salarial } \\
\text { está sendo respeitado, antes mesmo } \\
\text { da criação do plano, sendo que } \\
\text { no presente ano foi promulgada a } \\
\text { Lei } 3.865 / 17 \text { e } 03 \text { - O Município } \\
\text { possibilita atualmente a atuação e } \\
\text { permanência. } \\
\text { Status: Cumpridos } \\
02 \text { - Pela nova reformulação do } \\
\text { Estatuto, tal dispositivo será previsto } \\
\text { expressamente. } \\
\text { Status: em execução. } \\
04 \text { - A estratégia ainda não está } \\
\text { sendo cumprida por falta de previsão } \\
\text { legal, sendo que a mesma será } \\
\text { regulamentada na reformulação do } \\
\text { Estatuto do Magistério. } \\
\text { Status: Não cumprida. }\end{array}$ & $\begin{array}{l}\text { Meta } 17 \text { - Para que haja a execução } \\
\text { dessa meta faz-se necessário que } \\
\text { se façam as devidas correções no } \\
\text { Estatuto do Magistério que está em } \\
\text { andamento. }\end{array}$ \\
\hline $\begin{array}{l}\text { Meta } 18 \text { - Não há dotação } \\
\text { orçamentária tipificada no } \\
\text { Orçamento Municipal de Jataí de } \\
2017 \text { para a execução desta meta. } \\
\text { Os investimentos incidem nos } \\
\text { orçamentos da Educação Infantil e do } \\
\text { Ensino Fundamental. }\end{array}$ & $\begin{array}{l}\text { Meta } 18 \text { - Avaliação das } 03 \\
\text { estratégias: } \\
01 \text { - A reformulação do Plano está em } \\
\text { tramitação pela Comissão formada } \\
\text { para tal fim, mas considerando o } \\
\text { prazo, o mesmo encontra-se vencido. } \\
\text { Status: Em execução. } \\
02 \text { - O Fórum já está com data } \\
\text { definida, devendo referida estratégia } \\
\text { ser levada em conta. } \\
\text { Status: Não cumprido. } \\
03 \text { - A reformulação do Plano está em } \\
\text { tramitação pela Comissão formada } \\
\text { para tal fim. } \\
\text { Status: Cumprido. }\end{array}$ & $\begin{array}{l}\text { Meta } 18 \text { - No ano de } 2018 \text { muitos } \\
\text { profissionais da educação tiveram } \\
\text { suas progressões assinadas, mas ainda } \\
\text { há divergência de valores em caso de } \\
\text { mudança de titularidade. } \\
\text { O Estatuto do Magistério reformulado } \\
\text { precisa ser apresentado à categoria } \\
\text { pela comissão de elaboração para } \\
\text { que os profissionais da educação } \\
\text { conheçam os seus direitos e que } \\
\text { os mesmos sejam garantidos para } \\
\text { servidores contratados também. }\end{array}$ \\
\hline
\end{tabular}

Fonte: Cruvinel, Oliveira e Nez (2019). Dados extraídos dos Relatórios de monitoramento e avaliação. Disponível em: https://www.jatai.go.gov.br/ secretaria-de-educacao/plano-municipal-de-educacao/. Acesso em: 30 ago. 2019.

O Relatório de monitoramento do ano de 2016 não foi relacionado no quadro, pois todas as metas estavam em branco. Nesse sentido, os estudos de Raimann e Farias (2019, p. 74) assinalam que 
se como um guia informativo e deixa de cumprir o seu papel de avaliação e ou monitoramento de uma política pública que define metas escalonadas cronologicamente que estrutura a educação por uma década.

Por sua vez, o relatório de monitoramento apresentado no ano de 2017 informa que não houve dotação orçamentária para a execução das quatro metas que se referem à formação e trabalho docente, o qual pode ser analisado na primeira coluna do quadro 02. A avaliação do conjunto de metas de formação, trabalho/carreira apresenta os seguintes status:

- Meta 15 - cinco estratégias: a primeira, a terceira e quarta encontram-se em execução e a segunda e a quinta não foram cumpridas;

- Meta 16 - dez estratégias: que se apresentam com a mesma redação, como mostra o quadro 2 e como evidenciam os estudos de Raimann; Farias (2019);

- Meta 17 - quatro estratégias: a primeira e a terceira recebem o status de cumpridas; a segunda encontra-se em execução e a quarta deixou de ser cumprida;

- Meta 18: três estratégias: a primeira em execução, a segunda não cumprida e a terceira e última cumpridas.

Essa descrição permite afirmar que parte significativa das estratégias está em execução e aquelas que foram cumpridas, sinalizam que não há rubrica orçamentário-financeira e voltam-se para questões de organização e gestão da Rede.

Avançando, no Relatório de Monitoramento de 2018, na meta 15 o texto está em branco; na meta 16, a redação é modificada em relação aos outros relatórios, não apresentando a divisão por estratégias. São feitas menções às “assinaturas” de progressões na carreira para alguns docentes, mas com discrepâncias salariais, alerta para a necessidade de representatividade na reorganização do plano de carreira do município e aponta que muitas das ações do PME que se referem à formação e ao trabalho do professor são dependentes desse processo de revisão.

Com a finalidade de (re)adequação ou reestruturação do Estatuto e o Plano de Cargos e Vencimentos dos Profissionais do Magistério do Município de Jataí/GO foi montada uma comissão, coordenada pela Secretaria Municipal de Educação, cujas reuniões são realizadas na sede do Sindicato dos Trabalhadores em Educação do Estado de Goiás (SINTEGO). Contudo, o principal desafio não é, certamente, a reformulação do texto com vistas a melhores condições de formação e trabalho, mas a aprovação de um Estatuto que dê garantias ao docente para o exercício de sua profissão de forma autônoma, uma vez que na exposição de motivos do PME - assinada pelo prefeito à época da aprovação do PME (2015), o representante do Executivo afirma, ao fazer uma avaliação acerca da educação nacional e no município, que:

[...] o município de Jataí em função de possuir um plano de cargos e salários mais generosos do que os dos Governos Estadual e Federal, tem investido muito em pessoal na educação, mas isso não tem trazido grandes resultados, pois nosso IDEB está atrás de muitos municípios goianos.

- Que o alto nível de graduação dos nossos professores municipais, e também os investimentos em tecnologia como por exemplo os laboratórios de informática, também não tem colocado a educação municipal de Jataí entre as primeiras do Estado de Goiás (JATAÍ, 2015, p.6). 
A perspectiva que orienta a afirmação acima não é aquela que se baseia no trabalho e no trabalho docente enquanto condição para a formação humana, mas na direção da encruzilhada que credita os resultados da escola especialmente ao fazer do professor, desconsiderando as muitas dimensões envolvidas nesse processo. A percepção é que, mesmo com o esforço da comunidade em organizar-se em torno de um PME que contemplasse suas expectativas por uma educação de qualidade social, o município caminha sob bases neoliberais: da produtividade, flexibilidade, eficiência, eficácia e gestão administrativa. Isso é perceptível na exposição de motivos do projeto de lei do PME, enviada à Câmara Municipal, onde se lê:

Quanto a Jataí o nosso desafio será como otimizar os investimentos do município em educação, para isso não podemos tratar igualmente os desiguais:

- Não podemos mais tratar igualmente os excelentes professores que temos, professores qualificados, dedicados que produzem excelentes alunos, com aqueles professores graduados ou pós-graduados mas descompromissados, desinteressados e que produzem alunos despreparados. (JATAÍ, 2015, p.6).

Diante disso, o docente é responsabilizado e o compromisso, o interesse e a qualificação são entendidos como se essas fossem qualidades absolutamente próprio-inerentes ao indivíduo, e não resultado de um processo de desenvolvimento profissional para o qual é preciso haver investimentos públicos. Esse cenário aponta, portanto, para uma orientação de formação, trabalho e carreira docente compatível com um modelo de sociedade que valoriza a competitividade e a exclusão.

\section{Considerações finais}

Numa análise detalhada das metas do PME de Jataí/GO, percebe-se que, até 2019, 16 metas não haviam sido cumpridas e apenas quatro foram cumpridas parcialmente. Além disso, algumas delas estão longe de serem atingidas, pois se encontram apenas inicialmente articuladas para sua execução. Essa análise tem sido empreendida em diversos municípios no âmbito do projeto interinstitucional ao qual essa pesquisa se vincula. Especificamente sobre o município de Jataí/GO outros estudos sobre os desdobramentos do PME e a organização da educação municipal socializam e divulgam essa situação.

Os resultados revelam, ainda, que o PME também tem sido alvo de disputas de projetos políticos e educacionais como evidencia a divergência na redação entre os relatórios de monitoramento em tela. O primeiro destaca que não houve investimento, enquanto que, o segundo apresenta respostas variadas nas estratégias, assim podemos demonstrar que na mesma administração pública os interesses são divergentes, variando de acordo com a equipe que compõe a Secretaria Municipal de Educação. E o terceiro, na meta 15, deixa em branco. Enquanto que nas demais há justificativa que o Estatuto e o Plano de Cargos e Vencimentos dos Profissionais do Magistério do Município de Jataí/GO já estão em sendo corrigido.

Especificamente em relação à formação e trabalho docentes, verifica-se que o documento local é uma mera reprodução do PNE (2014-2024), desconsiderando o diagnóstico que aponta para necessidades formativas e de carreira específicas do município. (JATAÍ, 2015). Os relatórios de acompanhamento e avaliação do Plano apontam, ainda, que nenhum prazo estabelecido para a implementação das metas e estratégias relativas à formação e trabalho docente havia sido integralmente cumprido até 2018 (data do último relatório). 
Mesmo com o plano em vigência, aconteceram iniciativas pontuais para a articulação de ações que se aproximassem de uma política local de formação docente e de debates acerca do plano de carreira dos profissionais da educação, caminhando, assim, de forma muito lenta para o caminho de uma educação emancipatória.

Para concluir, retoma-se a pergunta norteadora do estudo e nota-se que há um esvaziamento do PME, o que desperta incertezas quanto às garantias do desenvolvimento dos profissionais de educação do município. Esse cenário de desenvolvimento e monitoramento das metas do PME aponta para a conclusão de que dificilmente esse Plano contribuirá, efetivamente, para uma política pública municipal comprometida com uma proposta de educação pública de qualidade socialmente referenciada.

\section{Referências}

ABBAGNANO, Nicolas. Dicionário de Filosofia. Tradução da $1^{\text {a }}$ edição brasileira coordenada e revista por Alfredo Bosi. Revisão da tradução e tradução dos novos textos por Ivoni Castilho Benedetti. 5. ed. São Paulo: Martins Fontes, 2007. Disponível em: http://charlezine.com.br/wpcontent/uploads/2011/11/Dicionario-de-Filosofia-Nicola-ABBAGNANO.pdf. Acesso em: 27 ago. 2017.

BARDIN, Laurence. Análise de conteúdo. 4. ed. Lisboa: Edições 70, 1977.

BRASIL. [Constituição (1988)]. Constituição da República Federativa do Brasil. [recurso eletrônico] -- Brasília, DF: Supremo Tribunal Federal, Secretaria de Educação, 2018. 514 p. Atualizada até a EC n. 99/2017. Disponível em http://www.stf.jus.br/arquivo/cms/legislacao Constituicao/anexo/CF.pdf. Acesso em: 27 mar. 2019.

BRASIL. CNE. CP. Resolução CNE/CP n ${ }^{\circ}$, de 15 de maio de 2006. Institui Diretrizes Curriculares Nacionais para o Curso de Graduação em Pedagogia, Licenciatura. 2006. Diário Oficial da União, Brasília, 16 de maio de 2006, Seção 1, p. 11. Disponível em: http://portal.mec.gov.br/cne/arquivos/pdf/ rcp01_06.pdf. Acesso em: 24 out. 2019.

BRASIL. LDB: Lei de diretrizes e bases da educação nacional. - Brasília: Senado Federal, Coordenação de Edições Técnicas, 2017. 58 p. Atualizada até março de 2017. Disponível em: http:// www2.senado.leg.br/bdsf/bitstream/handle/id/529732/lei_de_diretrizes_e_bases_1ed.pdf. Acesso em: 30 jul. 2019.

BRASIL. Lei do Plano Nacional de Educação de n. 10.172, de 09 de janeiro de 2001. Aprova o Plano Nacional de Educação e dá outras providências. Diário Oficial da União, Brasília: DF, 10 de janeiro de 2001. Disponível em: http://portal.mec.gov.br/arquivos/pdf/L10172.pdf. Acesso em: 12 jun. 2019

BRASIL. Lei do Plano Nacional de Educação de n. 13.005, de 25 de junho de 2014. Aprova o Plano Nacional de Educação - PNE e dá outras providências. Diário Oficial da União, Brasília, 26 de junho de 2014a. Disponível em: http://www.planalto.gov.br/ccivil_03/_ato2011-2014/2014/lei/113005.htm. Acesso em: 04 ago. 2017. 
BRASIL, Maggie Nunes. A pedagogia contida na forma de produzir capitalista. In: MASCARENHAS, Ângela Cristina Belém (org.). Educação e trabalho na sociedade capitalista: reprodução e contraposição. Goiânia: Editora ECG, 2005, p. 9-48.

BRASIL. Ministério da Educação. Planejando a próxima década: conhecendo as 20 metas do Plano Nacional de Educação. Brasília, 2014b. Disponível em: http://pne.mec.gov.br/images/pdf/pne_ conhecendo_20_metas.pdf. Acessado em: 21.02.2017.

BRASIL. Ministério da Educação. PNE em Movimento. Monitoramento e avaliação dos planos subnacionais de educação. Brasília, MEC, 2019. <http://pne.mec.gov.br/18-planos-subnacionais-deeducacao/37-monitoramento-e-avaliacao-dos-planos-subnacionais-de-educacao $>$. Acesso em: 20 out. 2019.

FRIGOTTO, Gaudêncio. As novas e velhas faces da crise do capital e o labirinto dos referenciais teóricos. In: FRIGOTTO, Gaudêncio; CIAVATTA, Maria (orgs.). Teoria e educação no labirinto do capital. $4^{\mathrm{a}}$ ed. São Paulo: Expressão Popular, 2016. p.45-85.

GATTI, Bernadete. A. A construção da pesquisa em educação no Brasil. Brasília: Líber Livro, 2007.

HELOANI, Roberto. Modelos de gestão e educação: gerencialismo e subjetividade. São Paulo: Cortez, 2018.

JATAÍ. Lei n. 2.822 de 27 de agosto de 2007. Dispõe sobre o Estatuto e o Plano de Cargos e Vencimentos dos Profissionais do Magistério do Município de Jataí - GO e dá outras providências. Diário Oficial do Município de Jataí-GO, 27 de agosto de 2007. Disponível em: http://sislegis. camarajatai.go.gov.br/portal//seeker?iddoc=1210. Acesso em: 13 maio 2019.

JATAÍ. Plano Municipal de Educação, Lei n. 3.708/2015, de 26 de junho de 2015. Aprova o Plano Municipal de Educação - PME para o próximo decênio, e dá outras providências. Diário Oficial Eletrônico do Município de Jataí-GO. Jataí, GO, 26 de junho de 2015. PME. Disponível em: https://www.jatai.go.gov.br/secretaria-de-educacao/plano-municipal-de-educacao/. Acesso em: 30 ago. 2019.

JATAÍ. Plano Municipal de Educação: avaliando o biênio 2015-2017 - versão preliminar. Disponível em: https://www.jatai.go.gov.br/secretaria-de-educacao/plano-municipal-de-educacao/. Acesso em: 30 set. 2019.

JATAÍ. Secretaria Municipal de Educação. Relatório monitoramento e avaliação do Plano Municipal de Educação de Jataí. Jataí, 2016. Disponível em: https://www.jatai.go.gov.br/secretariade-educacao/plano-municipal-de-educacao/. Acesso em: 30 ago. 2019.

JATAÍ. Secretaria Municipal de Educação. Relatório de monitoramento 2017. Jataí, 2017. Disponível em: https://www.jatai.go.gov.br/secretaria-de-educacao/plano-municipal-de-educacao/. Acesso em: 30 ago. 2019.

MARX, Karl. Manuscritos econômicos-filosóficos. Textos filosóficos. Edições 70. Lisboa: Editorial Boitempo, 1993. 
MASCARENHAS, Ângela Cristina Belém. Educação, trabalho e política: uma relação inevitável. In: MASCARENHAS, Ângela Cristina Belém (org.). Educação e trabalho na sociedade capitalista: reprodução e contraposição. Goiânia: Editora UEG, 2005, p. 161 -170.

RAIMANN, Ari; FARIAS, Rosângela Henrique da Silva. Monitoramento e avaliação do PME de Jataí-GO: desafios da educação. Laplage em Revista (Sorocaba), vol.5, n.3, set.- dez. 2019, p.67-77. Disponível em: http://www.laplageemrevista.ufscar.br/index.php/lpg/article/view/687/961. Acesso em: 30 set. 2019.

SAVIANI, Dermeval. O trabalho como princípio educativo frente às novas tecnologias. In: SAVIANI, Dermeval. Novas tecnologias, trabalho e educação. Petrópolis: Vozes, 1994. Disponível em: http:// www.ufpr.cleveron.com.br/arquivos/EP_104/demerval_saviani.pdf. Acesso em: 23 fev. 2015.

SAVIANI, Dermeval. Sobre a natureza e especificidade da educação. Em Aberto, ano 3, n. 22 , jul./ago. de 1984. p. 1-7. Disponível em: http://emaberto.inep.gov.br/index.php/emaberto /article/ view/1515/1490. Acesso em: 13 maio 2017.

SAVIANI, Dermerval; DUARTE, Newton. A formação humana na perspectiva histórico-ontológica. Revista Brasileira de Educação, Rio de Janeiro, v. 15, n. 45, set./dez. 2010. Disponível em: http:// www.scielo.br/pdf/rbedu/v15n45/02.pdf. Acesso em: 18 de ago. 2018.

SHIROMA, Eneida Oto; EVANGELISTA, Olinda. Formação Humana ou produção de resultados? Trabalho docente na encruzilhada. Revista Contemporânea de Educação, Rio de Janeiro, v. 10, n. 20, jul./dez. 2015. Disponível em: https://revistas.ufrj.br/index.php/rce/article/view/2730. Acesso em: 18 maio 2018.

SHIROMA, Eneida Oto; EVANGELISTA, Olinda. Avaliação e responsabilização pelos resultados: atualização nas formas de gestão de professores. Perspectiva, Florianópolis, v. 29, n. 1, 127-160, jan./jun. 2011. Disponível em: https://periodicos.ufsc.br/index.php/ perspectiva /article/view/2175795X.2011v29n1p127/19415. Acesso em: 24 mar. 2018. 